\title{
Small-volume subdural injection with extensive cephalad spread
}

\author{
John C. Drummond, MD, FRCPC • Roland R. Lee, MD
}

Received: 9 April 2020/Revised: 13 April 2020/Accepted: 13 April 2020/Published online: 21 April 2020

(C) Canadian Anesthesiologists' Society 2020

A 15-yr-old female (who consented to this report) underwent a major colorectal operation. A lumbar epidural catheter was placed preoperatively but yielded inadequate postoperative analgesia in spite of manipulations of catheter position. It was removed, and on the following day a second epidural catheter was placed in the T11-12 interspace. No paresthesia occurred and aspiration was negative for cerebrospinal fluid and blood. Because of the difficulty with the previous epidural, $3 \mathrm{~mL}$ of non-ionic contrast was injected through the catheter to verify correct placement. Anterior-posterior and lateral portable chest $\mathrm{x}$-rays (supine position) were obtained immediately after injection (Figure). The radiocontrast is seen in a dense, thin, cephalad column characteristic of subdural injections, ${ }^{1}$ extending up to the level of the C7-T1 interspace. The $x$-ray characteristics of intrathecal and epidural injection were not evident. Intrathecally injected non-ionic contrast, which is miscible in cerebrospinal fluid, disperses rapidly. With sufficient volume, the thecal sac fills homogeneously with contrast and the typical myelographic appearance becomes evident. Epidural injection yields local spread, in particular in the direction of the intervertebral foramina along the exiting nerve root sheaths, resulting in a dispersed, feathery, "Christmas-treelike" pattern. ${ }^{2}$ The present injection yielded the sharply delineated pattern that is characteristic of subdural injections. ${ }^{1}$ The catheter was removed without additional injections.

The subdural space is a potential space between the dura and the immediately subjacent pia-arachnoid mater. ${ }^{3}$ The possibility for injections into this space is reasonably well known to anesthesiologists as an explanation for incomplete blocks and unusual distributions of anesthetic effect. ${ }^{4}$ Most prior radiologic demonstrations of the subdural space have entailed lumbar injections of larger volumes of radiocontrast with greater lateral spread and

J. C. Drummond, MD, FRCPC ( $₫)$

Anesthesia Service, VA Medical Center, Department of

Anesthesiology, The University of California, San Diego, CA,

USA

e-mail: jdrummond@ucsd.edu

R. R. Lee, MD

Radiology Service, VA Medical Center, Department of

Radiology, The University of California, San Diego, CA, USA 


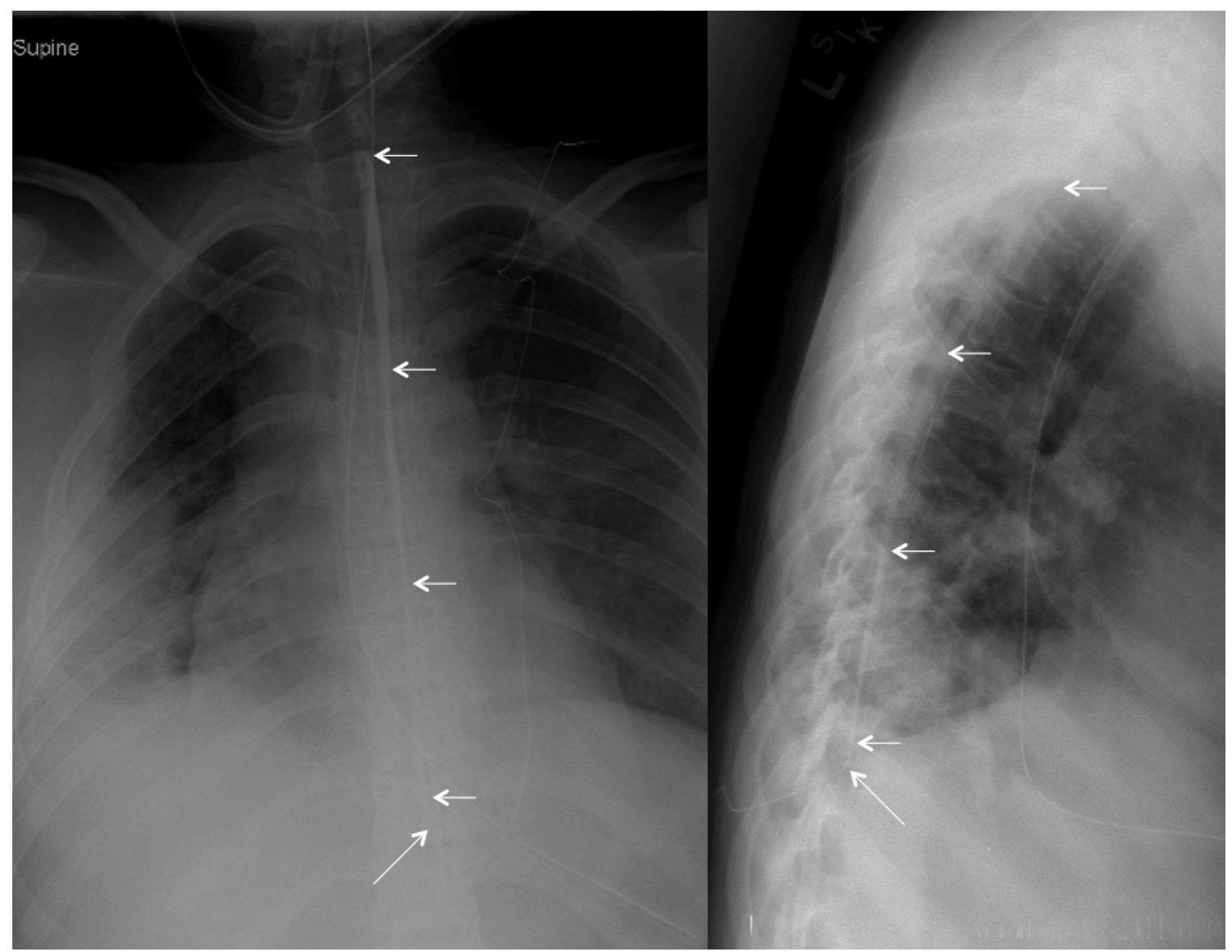

Figure Anterior-posterior (left) and lateral (right) radiographs taken immediately after injection of $3 \mathrm{~mL}$ of radiocontrast through an epidural catheter placed at the T11-12 interspace. An extensive

more limited vertical distribution. ${ }^{1}$ These present images show the potential for remarkably wide distribution of a small volume of injectate, and therefore of anesthetic effect, when subdural injection occurs at thoracic levels. It is possible that more extensive spread will sometimes occur because the spinal canal is narrower in the thoracic region.

Acknowledgements We are grateful to the patient for permission to publish the images.

Disclosures None.

\section{Funding None.}

Editorial responsibility This submission was handled by Dr. Hilary P. Grocott, Editor-in-Chief, Canadian Journal of Anesthesia. vertical column of radiocontrast is evident in the subdural space. Horizontal arrows indicate the radiocontrast column. Diagonal arrows indicate the tip of the epidural catheter

\section{References}

1. Collier $C B$. Accidental subdural block: four more cases and a radiographic review. Anaesth Intensive Care 1992; 20: 215-25

2. Johnson BA, Schellhas KP, Pollei SR. Epidurography and therapeutic epidural injections: technical considerations and experience with 5334 cases. AJNR Am J Neuroradiol 1999; 20: 697-705.

3. Reina MA, De Leon CO, Lopez A, De Andres JA, Mora M, Fernandez $A$. The origin of the spinal subdural space: ultrastructure findings. Anesth Analg. 2002; 94: 991-5.

4. Collier $C B$. Accidental subdural injection during attempted lumbar epidural block may present as a failed or inadequate block: radiographic evidence. Reg Anesth Pain Med. 2004; 29: 45-51.

Publisher's Note Springer Nature remains neutral with regard to jurisdictional claims in published maps and institutional affiliations. 